\title{
0 Efeito das Emendas ao Orçamento no Comportamento Parlamentar e a Dimensão Temporal: Velhas Teses, Novos Testes*
}

\author{
Fabricio Vasselai ${ }^{1}$ \\ Umberto G. Mignozzetti2 \\ ${ }^{1}$ Doutorando, Universidade de São Paulo (USP). São Paulo, SP, Brasil. E-mail: \\ fabriciovasselai@usp.br \\ ${ }^{2}$ Pesquisador da New York University. New York, Estados Unidos. E-mail: \\ umberto.mig@gmail.com
}

\section{INTRODUÇÃO}

$\mathrm{E}$ ste artigo faz uma reavaliação da influência da execução de emendas parlamentares individuais ao orçamento sobre o quão próximo os deputados votam dos interesses do Executivo nas votações nominais em plenário. Consideramos que tanto os trabalhos que defendem a influência das emendas na atuação dos parlamentares, como aqueles que tentam negá-la, deixaram lacunas importantes que mantêm a questão inconclusa. Em especial, esses estudos geralmente não abordam o fator tempo nos testes realizados, ou, nas raras oportunidades em que o fazem, apresentam problemas que levantam dúvidas sobre os resultados encontrados - justificando-se assim a pertinência de uma nova avaliação. Com base em dados para o período de 1996 a 2010, utilizamos modelos do tipo painel (time series-cross section) esti-

\footnotetext{
* Este artigo foi iniciado no âmbito do projeto de pesquisa "O Congresso Brasileiro no contexto do presidencialismo de coalizão", realizado no Núcleo de Pesquisa de Políticas Públicas da Universidade de São Paulo (NUPPS-USP), com apoio da Fundação Konrad-Adenauer. Agradecemos a ambas as instituições e aos colegas do projeto. Além deles, agradecemos particularmente os comentários e sugestões feitos por Fernando Limongi, José Álvaro Moisés, Sérgio Praça, Leandro P. Carneiro, Maria do Socorro S. Braga e Luciana F. Veiga. Vale ressaltar também a importância dos pareceres anônimos dados ao texto original. As deficiências remanescentes, é claro, seguem sendo de nossa inteira responsabilidade. Ambos os autores agradecem ainda o financiamento da Fundação de Amparo à Pesquisa do Estado de São Paulo (Fapesp).
}

DADOS - Revista de Ciências Sociais, Rio de Janeiro, vol. 57, no-3, 2014, pp. 817 a 853. 
mados pelo método de momentos generalizados (GMM, na sigla em inglês). O objetivo é, por um lado, avaliar a possível defasagem temporal entre a execução de emendas individuais ao orçamento e as votações em plenário. E por outro tratar os efeitos do caráter autorregressivo desse tipo de análise, em que a autocorrelação serial é um problema pouco enfrentado.

Nas duas últimas décadas, a Ciência Política brasileira tem sido pródiga em encontrar comprovações empíricas (Figueiredo e Limongi, 1999, 1998, 2002; Nicolau, 2000; Santos, 2003; Desposato, 2006, entre outros) que refutam os argumentos clássicos, sempre pressupostos e raramente testados, de que o sistema político brasileiro não funcionaria adequadamente. Esses argumentos pressupõem que o sistema político brasileiro seria personalista na arena legislativa, por simples decorrência de supostos incentivos personalistas advindos da arena eleitoral (principalmente ligados ao sistema proporcional de voto em lista não ordenada). Tal cenário resultaria em partidos fracos, desorganizados e indisciplinados na arena parlamentar, que impõem aos presidentes brasileiros sérias dificuldades para a formação de maiorias, para a aprovação de sua agenda política e para sua capacidade de governar e de fazer reformas estruturais (ver, entre outros, Ames, 2001; Lamounier, 1994; Mainwaring, 1991).

A principal refutação dessa linha de raciocínio coube a Figueiredo e Limongi (1999, entre muitos artigos). Esses autores mostraram que os partidos políticos na democracia brasileira atual são coesos e disciplinados nas votações em plenário, que muitas votações são decididas pelas lideranças partidárias (ou seja, os partidos seriam fortes na agregação de preferências) e que a agenda do Executivo é bem-sucedida na quase totalidade dos projetos votados. Do ponto de vista desses novos autores, o efeito microinstitucional que constrangeria os parlamentares a essa forma de atuação partidária e não pessoal seria resultado, sobretudo, dos poderes de agenda do Executivo e da força regimental do colégio de líderes dentro das instâncias do Congresso Nacional ${ }^{1}$.

Contudo, o debate se mantém mais aberto no que diz respeito ao mecanismo pelo qual tais fatores institucionais imporiam a atuação partidária, a despeito dos ímpetos supostamente personalistas dos parlamentares. Uma série de autores considera que se trata, de fato, de uma coerção dos partidos sobre os deputados, seja porque eles preferem a negociação coletiva, seja porque abdicam de poderes para colherem os 
frutos das políticas implementadas coletivamente, ou ainda pela necessária visibilidade trazida pelo apoio ou rejeição a um presidente fortalecido (ver Figueiredo e Limongi, 1999; Amorim Neto e Santos, 2003; Santos, 2003). No entanto, outros trabalhos avaliam que essas explicações são excessivamente racionalizadas e não identificam qual seria a "moeda de troca" com a qual seria construído o apoio parlamentar. Para alguns desses autores, essa moeda de troca é ainda assim coletiva, partidária, via nomeações ministeriais (Amorim Neto, 2000, 1998, 1994; Meneguello, 1998; Vasselai, 2009). Para outros, a "moeda de troca" circularia no varejo, sendo dada a cada parlamentar individualmente na forma de emendas individuais que eles podem apresentar anualmente ao orçamento federal (Alston e Mueller, 2001; Ames, 2001; Pereira e Mueller, 2002, 2003; Pereira e Rennó, 2001, 2007; Raile, Pereira e Power, 2011).

Embora a apresentação da proposta de orçamento no Brasil seja uma prerrogativa exclusiva do Poder Executivo, há um pequeno espaço na rubrica de investimentos que pode ser incrementada pelos deputados mediante a elaboração de emendas coletivas (de bancadas regionais, estaduais e comissões), de relatoria (relatores e sub-relatores) e individuais. Essa parte do orçamento, no entanto, é autorizativa, não mandató$r_{i a^{2}}$, ou seja, o presidente tem o poder discricionário de executar ou não os gastos de acordo com suas prioridades e de acordo com a arrecadação efetiva. Nesse cenário, as análises que propõem um papel de destaque para as emendas ao orçamento na construção do apoio parlamentar aos governos enxergam dois diferentes momentos analíticos.

Primeiro, com vistas à arena eleitoral, os parlamentares almejariam levar recursos para seus redutos eleitorais para maximizarem suas chances de reeleição. Uma série de trabalhos deu atenção a esse primeiro passo do argumento, tentando ou provar o uso e o sucesso dessa tática (Ames, 2001; Pereira e Mueller, 2002, 2003; Pereira e Rennó, 2001, 2007), ou, pelo contrário, tentando refutá-lo (Figueiredo e Limongi, 2005, 2002, 2008; Mesquita, 2009).

Segundo, esses recursos supostamente utilizados com vistas à reeleição seriam buscados na arena legislativa por meio da proposição de emendas individuais ao orçamento federal. E a efetiva execução dessas emendas por parte do Executivo seria a moeda de troca cobiçada pelos parlamentares, e por intermédio dela eles aceitariam apoiar o governo. Evidências da existência desse papel das emendas sobre a disci- 
plina parlamentar em relação às posições do Executivo vêm sendo defendidas por trabalhos como os de Alston e Mueller (2001), Ames (2001), Pereira e Mueller (2002, 2003), Pereira e Orellana (2009), Raile, Pereira e Power (2011), Zucco Jr. (2009), enquanto foram questionadas basicamente por Figueiredo e Limongi $(2002,2005,2008)$. Pretendemos contribuir para esse debate, voltando a testar o impacto das emendas individuais ao orçamento sobre o comportamento legislativo, mas enfrentando algumas facetas do efeito temporal dessa relação: a defasagem entre os dois fenômenos, o efeito autorregressivo do apoio legislativo ao Executivo, o problema da autocorrelação serial, o problema da instrumentalização necessária à estimação nesse tipo de situação.

A seguir, reconstruímos em detalhes os termos desses debates. Primeiro, na próxima seção, apresentamos a discussão da literatura sobre o papel das emendas no apoio parlamentar ao Executivo. Em seguida, esmiuçamos como os autores vêm abordando a questão do efeito tempo, ou de algum tipo de endogeneidade, entre emendas e apoio parlamentar. Na sequência, explicamos as variáveis utilizadas e os modelos estatísticos propostos, e apresentamos os principais resultados. Por fim, apresentamos uma breve conclusão.

\section{O DEBATE SOBRE O PAPEL DAS EMENDAS AO ORÇAMENTO}

Uma das principais características da discussão em torno do uso de emendas individuais ao orçamento como moeda de troca para o apoio legislativo é a defesa ou a refutação de grande conjunto de pressupostos e de hipóteses, todos ao mesmo tempo. Pereira e Mueller, por exemplo, concordam com as interpretações tradicionais sobre os incentivos personalistas provenientes da arena eleitoral, e afirmam que "de um lado, as regras eleitorais (...), o multipartidarismo e o federalismo agem descentralizando o sistema político" (2003:737-738). Mas esses autores se alinham a Figueiredo e Limongi (1999) quando assumem, por outro lado, que "as regras internas do processo de decisão dentro do Congresso e os poderes constitucionais do presidente de legislar e de distribuir recursos políticos e financeiros proporcionam grandes incentivos para a centralização" (2003:737-738). Diferentemente de Figueiredo e Limongi, porém, derivam daí que:

os legisladores brasileiros têm votado consistentemente seguindo a indicação dos seus líderes partidários não só devido aos poderes legislativos e de controlar a agenda do Congresso assegurados ao presidente, 
mas também por perceberem que esse comportamento pode proporcionar acesso a benefícios controlados pelo Executivo, benefícios esses que têm um forte impacto nas estratégias de sobrevivência política dos parlamentares na esfera eleitoral. Em outras palavras, o voto partidário é a forma encontrada pelos parlamentares de sobreviver politicamente em um ambiente no qual o Executivo desfruta de uma situação institucional privilegiada nas suas negociações com o Legislativo (2003:741).

Ou seja, nesse conjunto de afirmações há pelo menos três que necessitam de comprovação: a) que cada parlamentar age individualmente na busca de recursos para seus redutos eleitorais ${ }^{3}$, b) que fazem isso trocando apoio disciplinado aos interesses do governo por liberação de verbas para suas emendas ao orçamento, e c) que levar esses recursos para seus supostos redutos eleitorais, afetaria positivamente suas chances de reeleição. Figueiredo e Limongi $(2005,2002)$ contestam essa linha interpretativa, porém afirmando, também eles, que pretendiam discutir os "argumentos examinando não só os aspectos empíricos envolvidos, mas também as suas pressuposições teóricas" (2005:740).

Os autores até ampliam o leque de temas com os quais discordam e colocam em xeque a ideia de que os parlamentares almejam as emendas para fins distributivistas, como sendo essa ideia "uma visão [equivocada] do processo orçamentário, que enfatiza sua propensão [dos deputados] a sacrificar as políticas nacionais em nome das locais e particularistas" (Figueiredo e Limongi, 2002:304). Isso porque os outros autores teriam avaliado erroneamente que "seria possível observar uma relação direta entre execução de emendas orçamentárias e continuidades das carreiras políticas. [Como se] taxas de reeleição [fossem] uma função direta da execução das emendas individuais ao orçamento" (ibidem:305). E para conseguir essas verbas possibilitadas pelas emendas, como funcionaria o modelo criticado por Figueiredo e Limongi? Esses autores assim o descrevem: "O Executivo seria forçado a barganhar com cada um dos parlamentares a cada nova medida que introduz" (ibidem:304), sendo que essa "ideia segundo a qual o Executivo se vê forçado a atender demandas alheias às suas próprias prioridades não encontra apoio nos dados" (ibidem:326).

Dessa discussão, portanto, é possível extrair pelo menos cinco grandes afirmações paralelas em torno da ideia de influência das emendas ao orçamento na atuação dos parlamentares em plenário. Ainda que nem sempre todas sejam compartilhadas por todos os autores que advogam 
essa influência, elas seriam: 1) o processo orçamentário é estruturado de modo a sacrificar sobremaneira as políticas nacionais em nome das locais e particularistas devido ao espaço ocupado pelas emendas dos parlamentares ao orçamento; 2) isso porque os deputados se aproveitariam desse espaço para tentar levar verbas para seus redutos eleitorais através de suas emendas ao orçamento federal; 3) já que, por suposto, essa aplicação de recursos nos redutos teria relação direta com as taxas de sucesso em tentativas de reeleição; e 4) para conseguir a liberação das verbas para suas emendas, os parlamentares as negociariam direta e pessoalmente em troca de seu apoio em plenário aos projetos do Executivo - uma negociação no varejo com cada parlamentar, já que o interesse é pessoal e não partidário; 5) a fim de construir sua base de apoio parlamentar, o Executivo acabaria tendo que atender demandas orçamentárias contrárias às que gostaria, desfigurando sua própria agenda orçamentária.

Muitos autores defenderam esses cinco pontos, com maior ou menor clareza, como Ames (2001), Mainwaring (1991), entre outros. Pereira e Mueller parecem basear-se nos argumentos 2, 3 e 4 . Ainda, muitos desses pontos são inclusive populares fora da academia: Mesquita tem razão quando afirma que também "o senso comum dá como estabelecido que parlamentares se elegem e reelegem por meio de práticas clientelistas/distributivistas. Eleitores ou votos são, para carregar nas tintas, comprados com a alocação 'esperta' e beirando o ilícito de recursos públicos" (2009:1). Já Figueiredo e Limongi, por sua vez, contestam todos os cinco pontos. O mais importante neste momento, porém, é salientar que, se, no geral, esses argumentos não são fáceis de comprovar ou refutar por completo, mesmo assim, ainda que a falha empírica de um deles desmonte uma parte da explicação teórica, isso não implica a negação empírica dos demais argumentos.

Vejamos a questão de se as emendas são realmente usadas para levar verbas aos redutos eleitorais dos deputados e se isso tem impacto sobre as chances de reeleição (pontos 2 e 3 ). Há contestações importantes a esses argumentos (Figueiredo e Limongi, 2005, 2002; Mesquita, 2009). No entanto, mesmo que se aceitem as duas proposições como verdadeiras, ainda assim, elas não bastariam para comprovar que as emendas são usadas como moeda de troca para que os parlamentares votem com o presidente, pois pode ser que todos recebam verbas provenientes de emendas, a despeito de sua disciplina ao governo, sem que haja um padrão relevante. O inverso também é correto: mesmo que 
também não se comprove grande sucesso eleitoral na estratégia de levar recursos de emendas para redutos eleitorais ou para o Estado de origem, pode ser que os parlamentares apostem nessa opção, dado que não têm certeza ex ante se este seria ou não um caminho proveitoso ${ }^{4}$. $\mathrm{O}$ mesmo se pode dizer dos outros argumentos: a negação ou comprovação de uns não implica em direta negação ou comprovação de todos os outros.

Vejamos por exemplo os argumentos 1 e 5, sobre os quais o seguinte cenário é igualmente descrito e interpretado tanto nos trabalhos de Pereira e Mueller $(2002,2003)$ como nos de Figueiredo e Limongi (2005, 2002): "a Constituição atual estabelece que o Executivo tem a prerrogativa exclusiva de iniciar toda e qualquer legislação relacionada a matérias orçamentárias, o que envolve o Plano Plurianual - PPA, a Lei de Diretrizes Orçamentárias - LDO e a Lei Orçamentária Anual - LOA" (Figueiredo e Limongi, 2002:313). É claro que o conjunto dos parlamentares pode tentar influenciar nas decisões sobre os diversos aspectos da lei final do orçamento no interior da Comissão Mista de Orçamento, incluindo, por exemplo, alocações de recursos, através de relatórios setoriais (Praça, 2013). Mas são as emendas que possibilitam, por um lado, alteração formal direta do orçamento; e por outro lado, a busca individual de alterações por parte de cada parlamentar. No entanto, a respeito de tal espaço reservado para as emendas parlamentares na alteração do orçamento, concordamos com Mesquita (2009:12) quando ela diz: "deve-se ressaltar que a maior parte dos gastos públicos é definida fora do ciclo orçamentário anual. De fato, definem-se no interior desse processo e estão ao alcance da intervenção dos parlamentares apenas os gastos com investimentos que representam em média, para o período desta análise, 4,9\% do total do orçamento" ${ }^{\prime 5}$.

Além disso, as emendas individuais são minoria se comparadas às emendas coletivas, de partidos ou blocos estaduais, ou às emendas feitas pela relatoria da Comissão Mista de Orçamento (CMO). Segundo os dados que a autora apresenta (ibidem:14), em levantamento sobre aqueles mesmos anos, as emendas individuais de parlamentares representam em média 7,82\% do total de emendas. Ora, se ambos os dados estão corretos, e se, em caso hipotético, os parlamentares tentassem emendar toda a verba da rubrica de investimentos, teríamos que a parcela média do orçamento geral do governo federal que foi afetada por emendas individuais entre 1996 e 2006 seria de apenas $0,3 \%$ (7,8 vezes 4,9$)$. Para piorar, "embora os parlamentares tenham direito de pro- 
por emendas aos projetos de lei [orçamentária] (...), eles somente podem fazê-lo se as emendas forem compatíveis com o Plano Plurianual elaborado pelo Executivo e com a Lei de Diretrizes Orçamentárias" (Pereira e Mueller, 2002:271; sobre a legislação ver Brasil, 1988: art. 166, $\S 4)$, ou seja, "parlamentares não podem criar novos programas, isto é, políticas públicas, por meio de emendas de qualquer tipo. Emendas apenas remanejam recursos por programas previamente contidos na proposta orçamentária enviada pelo Executivo" (Mesquita, 2009:13). Por fim, de todo modo, a aprovação das emendas não garante que o novo gasto modificado seja executado pelo Executivo, que pode efetivamente escolher quais dessas emendas executar - o que lhe confere enorme poder discricionário.

Assim, sobram poucas dúvidas de que, na verdade, emendas individuais ao orçamento não conseguem alterar o caráter nacional do orçamento do país (ponto 1); de que o Executivo não tem sua agenda orçamentária desfigurada e de que as emendas não têm muito peso nos gastos efetivados anualmente (ponto 5). Estas são questões interessantes para a literatura como um todo e para o grande grupo de pressupostos envolvidos no debate sobre o papel das emendas parlamentares. Mas, especificamente no que se refere ao seu impacto sobre o apoio parlamentar ao Executivo, não é determinante, a priori, que pequena parcela do orçamento possa ser emendada pelos parlamentares. Nem que a maioria das emendas seja do tipo coletivo e não individual. E se uma parte tão pequena do orçamento já for suficiente para fazer diferença no comportamento parlamentar? Nada impede que emendas individuais importem para os deputados, mesmo que ocupem parcela ínfima do orçamento federal.

De todo modo, vale observar que há diversos indícios de que as emendas parlamentares não podem passar de explicações no máximo parciais para o comportamento parlamentar. Algo salientado, a bem da verdade, inclusive pelos trabalhos recentes que argumentam sobre a importância das emendas (é o caso, por exemplo, de Raile, Pereira e Power, 2011). Uma intuição clara sobre isso já havia, contudo, sido defendida por Figueiredo e Limongi, que estão corretos quando ressalvam que muitos deputados que votam com o governo têm pouquíssima execução de emendas (2005:744). Ou quando ressalvam que "há deputados que emendam o orçamento e não exercem mandatos (logo, não votam) no ano de sua execução, e há deputados que votam, mas não participaram da elaboração do orçamento e, conseqüentemente, 
não têm emendas para serem liberadas" (idem:753). E, principalmente, quando recordam que, no agregado por partido, enquanto a execução de emendas varia a cada ano, a disciplina parlamentar pouco varia. $\mathrm{O}$ que aliás, por si só já deveria levantar a suspeita de presença de autocorrelação serial nas estimações.

Essas considerações nos ajudam a não circunscrever o papel das emendas para além de um fator explicativo adicional, se tiver algum papel, sobre a disciplina dos deputados federais. Mas nada disso nega ou inviabiliza esse papel a priori, do ponto de vista lógico, como os autores acima citados parecem, às vezes, sugerir. É por isso que neste trabalho não pretendemos encontrar comprovações / refutações empíricas para todas as proposições feitas em torno do assunto. Reconhecemos que, do ponto de vista teórico, não vamos explorar a questão proposta por Figueiredo e Limongi (2005:766), de que "o problema da tese das emendas como 'moedas de troca' está em seus supostos". Nosso interesse limita-se a reinvestigar, introduzindo adequadamente o fator tempo, o argumento número 4 mencionado acima. Qual seja, se a execução pelo Executivo das emendas introduzidas no orçamento federal por deputados afeta a proximidade desses parlamentares às preferências do Executivo nas votações nominais realizadas na Câmara.

\section{EFEITO TEMPO}

Para tentar responder a essa pergunta, separadas das outras afirmações que estão em sua órbita, cabe analisar rapidamente a importância do uso de modelos que considerem a dimensão temporal à luz das abordagens adotadas na literatura sobre o assunto. Do ponto de vista teórico, é realmente provável haver uma ordem cronológica específica na relação causal esperada entre emendas executadas e voto dos deputados em plenário: um fato não precisa necessariamente ser, e de fato provavelmente não é, simultâneo ao outro. Ou seja, os fatos podem responder, e provavelmente respondem, a tempos $t$ diferentes entre si.

Assim, o emprego de modelos estáticos para fazer o teste empírico dessa relação não é capaz de revelar adequadamente se a execução das emendas influencia ou não no comportamento parlamentar, caso não modelem seu caráter sequencial. Por um lado, deixar de incorporar esse caráter sequencial através da inclusão de termos com defasagem temporal, quando ele efetivamente existe, leva a um maior risco de surgirem resultados falsos negativos (erros do tipo II) quanto ao papel das emendas. Por outro lado, falsos positivos (erros do tipo I) também 
podem ocorrer: em primeiro lugar, devido à má especificação causada pela omissão de defasagem temporal, e em segundo lugar, pela possível presença de autocorrelação serial que é omitida quando não se considera a dimensão temporal. Conforme mencionamos acima, a julgar pelo que a literatura conhece a respeito das taxas de apoio ao Executivo, há motivos de sobra para esperar que esse apoio não varie bruscamente de um momentum (ano, mês etc.) para o outro. Ou seja, é provável que o apoio parlamentar em $t$ seja uma função do apoio parlamentar em $t$-1. Desconsiderar essa possibilidade de autocorrelação serial também leva à inconsistência dos estimadores e, por conseguinte, dos resultados. A investigação de uma possível relação entre emendas ao orçamento e apoio parlamentar ao Executivo é, portanto, mais intrincada do que parece.

Na série de artigos que avaliou empiricamente essa relação, Pereira e Mueller foram os primeiros a suspeitar desse caráter mais complexo e a desenvolvê-lo, quando afirmaram: "supõe-se que não apenas a forma de votar afeta a execução das emendas, mas que um parlamentar, cujas emendas fossem executadas, tenderia, ceteris paribus, a votar com mais freqüência a favor do governo. Existem, portanto, duas variáveis endógenas" (2002:283). Sua proposta era, por isso, a aplicação de um sistema de duas equações que estimasse a simultaneidade de causalidade entre ambos os fenômenos por meio da estimação similar ao que hoje é conhecido como Simultaneous Equation Models (SiEM). Ou seja, a execução de emendas por ano e o apoio legislativo por ano eram ambos variáveis dependentes, uma em cada equação, tendo a outra como uma de suas variáveis explicativas. O problema é que sua abordagem não resolvia o imbróglio, pelo contrário, confundia a possível ligação cíclica diacrônica entre as variáveis com uma endogeneidade sincrônica: "para garantir estimadores consistentes, dada a simultaneidade entre Votos e Execução, usamos variáveis instrumentais, isto é, variáveis que tenham correlação com a variável endógena do lado direito da equação, mas não se correlacionam com o termo de erro" (idem:284, ênfase nossa). Além disso, não apresentam e nem mesmo mencionam testes sobre a validade dos instrumentos utilizados, bem como nada falam sobre a identificação de seus modelos, o que é central em estimações desse tipo.

Ao mesmo tempo, se, em sua resposta a essa questão, Figueiredo e Limongi (2002:326) têm razão ao afirmarem que "dizer que se trata de um jogo que se repete no tempo é apenas uma forma de recolocar a 
questão", eles, por sua vez, embora reconheçam a existência do problema temporal, não chegam a adotar medidas para considerá-lo quando testam o impacto das emendas sobre o apoio parlamentar ${ }^{6}$. Aliás, a não incorporação do efeito temporal necessário para descortinar a aparente/possível endogeneidade entre essas variáveis já havia sido a opção de Ames (2001) e dos modelos formais de Alstom e Muller (2001), e continuou a ser no artigo seguinte de Pereira e Mueller (2003), bem como nas futuras contestações de Figueiredo e Limongi $(2005,2008)$.

O segundo trabalho a tratar empiricamente do problema da suspeitada endogeneidade entre execução de emendas e apoio parlamentar, veio apenas com Zucco Jr. (2009). Nesse estudo, o autor indica que: "Um último problema é a possibilidade de endogeneidade na variável PORK" (2009:1085, tradução nossa, ênfase no original), exatamente ao recuperar a afirmação de Pereira e Mueller de que "os desembolsos de pork podem ser tanto uma recompensa como uma sedução para os legisladores, e por essa razão eles afetam e são afetados pelos votos desses legisladores. Para lidar com esse problema, estimei meus modelos de pooled-data através do método de mínimos quadrados em dois estágios" (2009:1086, tradução e ênfases nossas). Tendo apenas uma variável dependente, que é a disciplina parlamentar relativa à posição do governo, Zucco Jr. não estima um modelo recíproco (ou seja, não recursivo) entre disciplina e emendas, como o de Pereira e Mueller (2002). E tampouco leva em conta o efeito temporal: assim como fizeram Pereira e Mueller (2002), Zucco Jr. utiliza variável instrumental (tempo de mandato dos parlamentares, uma variável que, como veremos mais adiante, será incluída em nossos modelos como controle) apenas para tentar lidar com a suposta endogeneidade simultânea entre execução anual de emendas (pork) e apoio parlamentar anual.

Nesses trabalhos pioneiros sobre a relação mais complexa entre tais variáveis, o problema estava, contudo, mal diagnosticado: elas não são necessariamente simultâneas. Elas existem ao mesmo tempo, mas é bem possível que respondam uma à outra em tempos $t$ diferentes. Nesse sentido, como comentamos, a desconsideração da defasagem temporal pode levar a resultados inconsistentes por problemas de especificação. A desconsideração do efeito tempo levou a uma outra deficiência ainda mais importante: nenhum trabalho sobre o assunto até então deixava claro se nos modelos haveria correlação serial de alguma ordem, o que é perfeitamente plausível na hipótese de haver defa- 
sagem temporal entre os fenômenos e também no caso de as variáveis serem uma função delas próprias em um tempo $t$ anterior.

A dimensão diacrônica, bem como o problema da autocorrelação serial, foram ambos explicitamente operacionalizados pela primeira vez num artigo de Pereira e Orellana (2009). Na verdade, esse artigo introduziu diversas novidades. Primeiro, além da execução das emendas individuais, eles também testaram pela primeira vez o impacto da execução das emendas estaduais sobre o apoio parlamentar ao Executivo. Segundo, a mensuração das variáveis foi feita por mês e não por ano, como havia ocorrido nos trabalhos anteriores. Terceiro, a agregação das variáveis: a unidade de análise deixou de ser os parlamentares (sua taxa de disciplina ao governo, seu voto favorável ou contrário em votações, as emendas de sua autoria que foram executadas etc.) e passou a ser o agregado do plenário: a porcentagem mensal de apoio conquistado em plenário e as execuções gerais mensais de emendas. Após a realização de testes diagnósticos de seus modelos, Pereira e Orellana reportam a presença de autocorreção serial de ordem 1, AR(1). Por esse motivo, apresentam os resultados em dois modelos: um estimado por uma regressão de mínimos quadrados ordinários com variáveis binárias temporais (o que seria um modelo LSDV, na sigla em inglês) e outro por estimação de Prais-Winsten (1954). O problema é que essa abordagem, embora eficiente de maneira geral para corrigir $\mathrm{AR}(1)$, não é capaz de corrigir $\operatorname{AR}(>1)$. Em especial, sendo a unidade temporal tão curta como meses, e conhecendo-se o caráter quase estacionário do apoio legislativo, é plausível imaginar que a autocorrelação esteja presente em períodos mais longos do que um mês. Dito de outro modo: é provável que, por exemplo, não seja apenas o apoio legislativo de um mês atrás que determine o apoio legislativo presente. O mesmo vale para a execução das emendas.

Raile, Pereira e Power (2011) incorrem em problema similar. Na realidade, sua proposta é mais complexa: eles estimam um sistema de quatro equações em que voltam a modelar o efeito recíproco (não recursivo) entre apoio legislativo e execução de emendas usando SiEM, mas agora consideram esse efeito como diacrônico. Seguem Pereira e Orellana no uso de unidade temporal mensal e seus objetos de análise também não são os deputados individualmente, mas o agregado da Câmara dos Deputados. Ou seja, querem verificar se em cada mês a execução geral de emendas individuais tem relação com a taxa mensal média de disciplina às preferências do Executivo por parte da Câmara 
como um todo. O resultado que encontram sugere que existe efeito recíproco: mais emendas executadas em um tempo $t_{0}$ reflete-se em maior apoio legislativo em um tempo $t_{1}$, o qual, por sua vez, leva a mais emendas em $t_{2}$ e assim por diante. No entanto, cabe ressalvar que o coeficiente encontrado pelos autores para o impacto das emendas sobre o apoio legislativo, quando se considera seu valor (à luz da unidade de medida das variáveis) e não apenas a direção de seu sinal, é pequeno. Por outro lado, o forte impacto sobre o apoio legislativo em um dado mês, segundo seus próprios resultados, advém justamente do apoio legislativo no mês anterior. Além disso, os autores citados chegam ao improvável (e não explicado) resultado de que o número de cadeiras da coalizão na Câmara em um dado mês não tem impacto sobre a porcentagem de apoio conseguido no plenário em geral nesse mês.

E o mais importante é que alguns detalhes metodológicos mostram como, nesse que é o segundo e principal trabalho a modelar a questão temporal, o problema ainda não está completamente elucidado. Primeiro, tal como Pereira e Orellana (2009), Raile, Pereira e Power detectam a presença de AR(1) e, para corrigi-la, incluem em todas as equações do sistema variáveis independentes, que são a defasagem em uma unidade temporal das variáveis dependentes. O problema é que, mais uma vez, sendo a unidade temporal tão curta quanto meses, e considerando o caráter quase estacionário do apoio legislativo, é provável que a autocorrelação atinja períodos mais longos. Raile, Pereira e Power afirmam que "essas defasagens eliminam as estruturas de erro autorregressivo" (2011:327; tradução livre). Contudo, sua nova solução com defasagens temporais de ordem 1 - é capaz de resolver o problema de autocorrelação de ordem 1, mas não necessariamente de outras ordens. Tampouco está claro se o modelo cíclico entre emendas e apoio legislativo ajuda a solucionar esse problema. Infelizmente, tal como no trabalho de Pereira e Orellana, Raile, Pereira e Power não trazem a informação sobre testes de $\operatorname{AR}(2)$ ou $\operatorname{AR}(>2)$. Conforme veremos adiante, em nossos modelos realmente sempre encontramos $A R(2)$, mesmo utilizando unidade temporal anual, ou seja, com distância cronológica entre as variáveis bem maior do que meses. E a correção desse problema em nossos modelos, como também veremos, é na verdade crucial, pois altera os resultados encontrados. Considerando que os autores usaram as defasagens temporais de suas variáveis dependentes como instrumentos para a estimação, cabe ressaltar que a questão da autocorrelação serial se torna especialmente importante, já que a presença 
de AR fragilizaria sua possibilidade de instrumentalizar (portanto, de identificar matematicamente) o sistema de equações empregado.

Um segundo problema que observamos no artigo de Raile, Pereira e Power (2011) tem a ver exatamente com a especificação necessária para estimar modelos SiEM não recursivos adotados por eles. Nesses modelos, em que $Y_{1}$ (apoio legislativo) é a variável explicativa de $Y_{2}$ (execução de emendas) e $Y_{2}$ é ao mesmo tempo explicativa de $Y_{1}$, é necessário utilizar como instrumentos algumas variáveis que afetem $Y_{2}$ apenas por intermédio de $Y_{1}$ e outras que afetem $Y_{2}$ apenas através de $Y_{1}$. A variável explicativa que aparece como exclusiva da equação em que a variável dependente é o apoio legislativo (fora o próprio apoio legislativo em tempo t-1) é o número de cadeiras da coalizão na Câmara Federal. Mas esse não poderia ser um fator de óbvio impacto direto também sobre a execução média de emendas? Parece claro que sim. Por outro lado, as variáveis explicativas que aparecem apenas na equação em que a execução de emendas é variável dependente (fora a própria execução de emendas em tempo $t$-1), são: heterogeneidade da coalizão, coalescência ministerial no sentido de Amorim Neto (2000) e popularidade presidencial. Mas, outra vez, essas variáveis não parecem ter evidente possibilidade de impactar diretamente sobre o apoio legislativo a despeito das emendas, prejudicando assim a instrumentalização dessa equação?

Infelizmente, não foram apresentados os testes necessários sobre a força ou mesmo a validade desses instrumentos. Como mencionamos, considerando a possibilidade da presença de AR não corrigida, tampouco há garantia de que os termos defasados estejam ajudando a instrumentalizar a estimação. Desse modo, a identificação dos modelos é incerta. Consequentemente, o ajuste e a validade desses modelos tornam-se também uma incógnita, e com possibilidade real de problemas $^{8}$.

Ainda que saibamos da e sejamos solidários à dificuldade de se encontrar instrumentos adequados, é sabido que os resultados encontrados com uso de instrumentos inadequados, ou modelos com identificação possivelmente fraca, devem ser lidos, no mínimo, com grande cautela. Outras saídas podem ser encontradas como instrumentos. Neste artigo, por exemplo, a fim de conseguir uma instrumentalização válida, optamos por usar ou a execução do orçamento federal nos estados a que pertencem os deputados (instrumento externo), ou a defasagem 
da variável dependente em ordens suficientemente grandes para ao mesmo tempo não permitir AR (instrumento interno). Como veremos nos resultados apresentados na próxima seção, ambas as opções passam também no teste Sargan de validade de instrumentos. Além disso, cabe adiantar que recuperaremos os deputados como unidades de análise, por considerarmos que a unidade de análise que agrega todo o plenário - utilizada nos últimos trabalhos sobre o tema - prejudica a possibilidade de verificar as diferenças entre situação e oposição, o que inviabiliza o controle do comportamento parlamentar pela pertença à base aliada, central para checar a robustez de qualquer efeito que se venha a encontrar para as emendas ao orçamento.

\section{MODELO ESTATÍSTICO}

A seguir, procedemos à nossa análise empírica tentando incluir a dimensão temporal nos termos mencionados anteriormente. Ou seja, primeiro, incluímos a defasagem temporal entre execução de emendas e apoio parlamentar; segundo, introduzimos a defasagem da variável dependente como modo de corrigir problemas de $\mathrm{AR}(2)$ e até de $\mathrm{AR}(>2)$. Para isso, especificamos modelos dinâmicos autorregressivos de efeitos fixos, estimados por difference GMM com variáveis instrumentais em geral e pelo método de Arellano-Bond (1991) em particular ${ }^{9}$. Terceiro, utilizamos os novos instrumentos GMM mencionados anteriormente. Iniciamos com a descrição dos dados, das variáveis e dos modelos estatísticos que serão utilizados, e na sequência, apresentamos os resultados das estimações - todas elas realizadas usando as funções do pacote $p l m$ do software estatístico $R$ em sua versão 3.01.

No que se refere às fontes utilizadas para os dados, as informações sobre emendas e execuções orçamentárias entre os anos de 1996 e $2010^{10}$ foram coletadas nos relatórios de execução orçamentária da Comissão Mista de Orçamento, na página da Câmara dos Deputados na internet ${ }^{11}$. Informações sobre votos dos deputados em plenário foram retiradas do Banco de Votações Nominais do Centro Brasileiro de Análise e Planejamento (Cebrap). Outras informações sobre os deputados foram catalogadas e computadas por intermédio dos dados de perfis biográficos disponibilizados pela Câmara dos Deputados. A organização dos dados tomou como unidade de análise cada deputado em cada ano ${ }^{12}$.

Para medir o quão próximo das preferências do Executivo cada deputado votou em cada ano, adotamos como variável dependente a distância dos votos dos parlamentares com relação à indicação de voto do lí- 
Fabricio Vasselai e Umberto G. Mignozzetti

Tabela 1

Descrição das Variáveis Empregadas

(Amostra: 1.278 Deputados com 1-15 pontos temporais, de 1996 a 2010)

\begin{tabular}{|c|c|c|c|c|c|c|c|}
\hline & Var. contínuas: & $\bar{X}$ & $\sigma$ & Mín. & $1^{\circ} Q$ & $3^{\circ} \mathrm{Q}$ & Máx \\
\hline Dgov & $\begin{array}{l}\text { Distância entre o ponto ideal de } \\
\text { um dado deputado e o do líder do } \\
\text { governo, nas votações nominais }\end{array}$ & ,27 & 23 & ,00 & ,08 & ,40 & 95, \\
\hline P-A & $\begin{array}{l}\% \text { de emendas individuais ao } \\
\text { orçamento de um dado deputado, } \\
\text { que foram liquidadas em relação } \\
\text { às aprovadas }\end{array}$ & ,72 &, 24 & ,00 &, 58 & ,92 & 1,72 \\
\hline OrcMinist & $\begin{array}{l}\% \text { de orçamento ministerial médio } \\
\text { controlado pelo partido de cada } \\
\text { deputado }\end{array}$ & 15 & ,22 & ,00 & ,00 & ,20 & ,90 \\
\hline AnosMandato & $\begin{array}{l}\text { Anos de mandato na Câmara } \\
\text { acumulados por cada deputado }\end{array}$ & 6,57 & 5,49 & 0 & 2 & 9 & 39 \\
\hline nPartCarreira & $\begin{array}{l}\text { № de partidos diferentes a que } \\
\text { cada candidato já foi filiado }\end{array}$ & 2,36 & 1,34 & 1 & 1 & 3 & 10 \\
\hline AnosPartAtual & $\begin{array}{l}\text { № de anos desde que cada } \\
\text { deputado é filiado ao partido em } \\
\text { um dado ano }\end{array}$ & 9,61 & 7,96 & 0 & 3 & 16 & 30 \\
\hline \multirow[t]{2}{*}{ uf_PLA } & $\begin{array}{l}\text { \% de emendas de bancadas } \\
\text { estaduais ao orçamento, que } \\
\text { foram liquidadas em relação às } \\
\text { aprovadas }\end{array}$ &, 50 & 20 & ,05 & ,37 & ,65 & 1,00 \\
\hline & Var. binária: & $=0$ & $=1$ & & & & \\
\hline $\mathrm{Coa}$ & $\begin{array}{l}\text { Pertencimento dos deputados à } \\
\text { coalizão }\end{array}$ & $33 \%$ & $66 \%$ & & & & \\
\hline
\end{tabular}

Fonte: Estimação própria.

der do governo (variável Dgov) ${ }^{13}$. Primeiramente, tomamos as votações nominais de todos os deputados, incluindo a indicação do líder do governo, em um dado ano. Aplicamos então o algoritmo W-Nominate, em sua versão implementada no pacote estatístico $R$, para estimar os pontos ideais (somente a primeira dimensão) de cada parlamentar/ano. Na construção dos seus escores, o W-Nominate estima, por máxima verossimilhança, o seguinte modelo:

$\ln L=\sum_{j=1}^{p} \sum_{j=1}^{q} \sum_{l=1}^{2} C_{i j l} \ln P_{i j l}$

em que $p$ é o número de legisladores, $q$ o número de votos e $l$ representa as duas alternativas possíveis (no caso, "a favor" ou "contra" a posição 
do líder do governo). A função $C$ é uma indicadora da escolha do candidato e a função $P$ reflete a probabilidade de o deputado votar a favor ou contra, dado o seu ponto ideal (função de resposta ao item). Após estimação dos valores ótimos para cada parâmetro, chegamos então aos pontos ideais de cada um dos legisladores e do líder do governo para cada ano. Uma vez calculados seus escores anuais (que variam de -1 a 1), calculamos então a distância entre os escores de cada deputado e o do líder do governo. Seja $p_{L G_{t}}$ o ponto ideal do líder do governo em um ano $t$ e $p_{i t}$ o ponto ideal de um parlamentar $i$ qualquer no mesmo ano $t$, tomamos o valor absoluto da subtração entre esses pontos e o dividimos por 2 para que a distância possa variar entre 0 e 1, sendo interpretada, portanto, como uma probabilidade.

$\operatorname{Dgov}_{i_{t}}=\frac{\left|p_{i_{t}}-p_{L G_{t}}\right|}{2}$

Esta abordagem utilizando pontos ideais permite que se obtenha uma medida de distância consistente com relação ao líder do governo, computando-se de maneira eficiente até mesmo as situações em que um deputado acabou não votando ou o líder acabou não indicando o voto ${ }^{14}$. $\mathrm{O}$ algoritmo do W-Nominate tem a vantagem de estimar corretamente a posição do parlamentar com relação ao eixo principal - que alguns autores como Leoni (2002) tendem a identificar como sendo ideologia. Além disso, o algoritmo possui alto poder preditivo (cerca de $90 \%$ ) e, ainda, ordena corretamente as posições dos deputados a despeito de uma ou outra ausência em votações ${ }^{15}$. Dito isso, a interpretação da variável Dgov é a seguinte: se igual a 0 , significa que o deputado analisado, no ano analisado, votou exatamente igual ao governo sempre (distância de zero para com o ponto ideal do governo); se igual a 0,5 significa que ele esteve a 50\% de distância do governo; e se igual a 1 significa que ele vota contra o governo sempre (distância máxima possível para com o ponto ideal do governo). Portanto, de 0 a 1 , quanto maior o valor de $D g o v$, maior o distanciamento do deputado em relação à preferência do governo no ano em questão ${ }^{16}$.

Como variáveis independentes de interesse, adotamos as seguintes. Primeiro, a execução de emendas de cada parlamentar por parte do Executivo em cada ano, que chamamos de PLA (percentual do liquidado ${ }^{17}$ pelo Executivo com relação ao autorizado pela peça orçamentária). Uma liberação de 1 (100\%) implica que o governo executou integralmente os valores das emendas que o parlamentar propôs e que 
foram autorizadas. Já PLA igual $0(0 \%)$ significaria que o governo não liberou quantia alguma do valor que fora autorizado para aquele parlamentar. A segunda variável principal de interesse é Coa, que indica se o partido do parlamentar considerado pertencia à coalizão de governo, isto é, se ocupava algum ministério em algum momento do ano em questão $^{18}(1=$ pertencia à coalizão ministerial naquele ano; 0 = não pertencia). Com ela será possível testar o papel da pertença à coalizão de governo sobre a proximidade do voto dos parlamentares em relação à preferência do Executivo.

Na Figura 1 apresentamos dois gráficos que permitem uma primeira descrição das relações entre essas três variáveis centrais nesta investigação: Dgov, PLA e Coa. O gráfico superior mostra a distribuição de PLA de acordo com Coa em cada ano. Ele permite perceber que, embora

\section{Figura 1}

Dgov (distância entre ponto ideal dos deputados e do governo), PLA (emendas liquidadas/autorizadas) e Coa (pertencimento à coalizão)

$$
\text { Coa } \mathfrak{t}_{0}: \text { oposição }=\text { coalizão }
$$
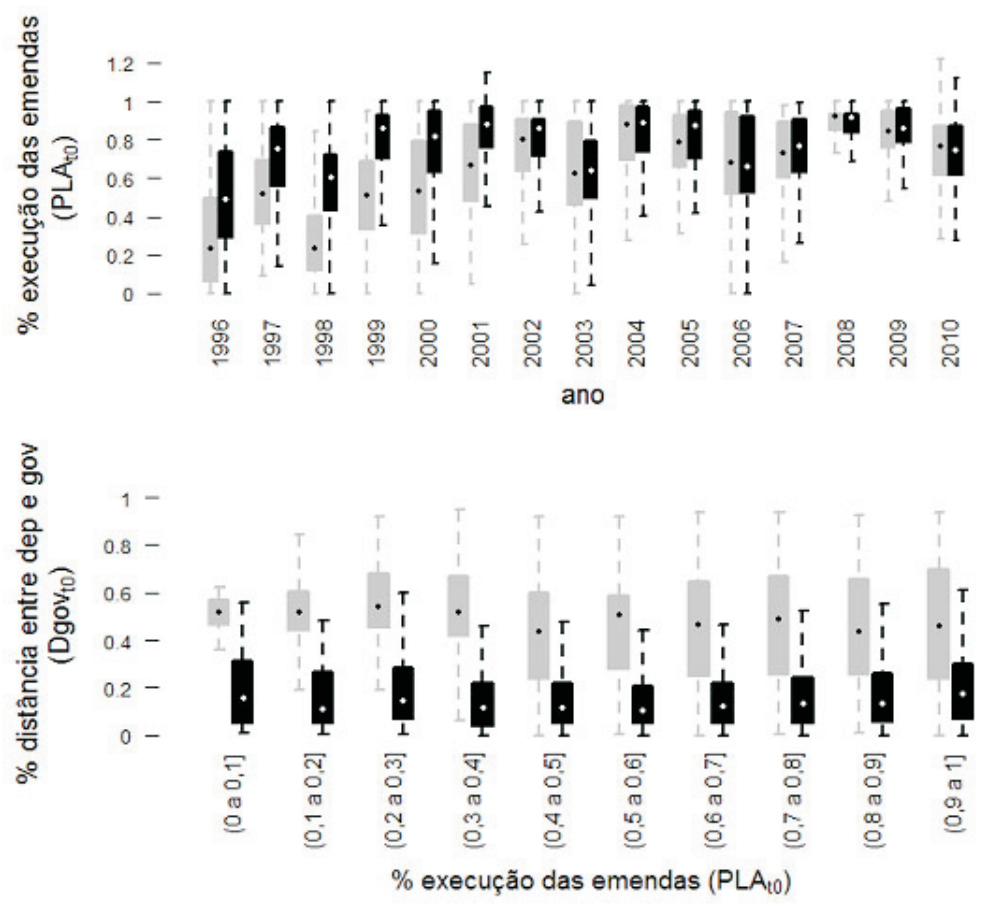

Fonte: Estimação própria. Obs.: Outliers omitidos. 
sempre com grande variabilidade, desde meados do governo Fernando Henrique Cardoso, a execução de emendas ao orçamento feitas por deputados cujos partidos não pertenciam às coalizões passou a ser cada vez mais elevada. Na verdade, o período mostra crescente e rápida convergência entre os padrões de execução de emendas de deputados de dentro ou de fora da base aliada dos presidentes. Além de sugerir menos importância para as emendas do que usualmente se imagina, do ponto de vista metodológico esse gráfico mostra também que não parece haver multicolinearidade entre PLA e Coa e, na verdade, qualquer efeito de PLA tende a não capitalizar na pertença à coalizão.

Já o gráfico inferior, contudo, permite visualizar em linhas gerais a relação entre patamares de execução de emendas e a proximidade entre os deputados e o governo. O eixo X traz PLA segmentada em intervalos de $10 \%$ e o eixo Y traz Dgov. Note-se que a julgar por essa primeira apresentação, no agregado, a distância entre o ponto ideal dos parlamentares e o ponto ideal dos governos pouco varia à medida que se avança para patamares superiores de PLA. Com exceção, talvez, de pequena aproximação na distância entre deputado e governo nos primeiros incrementos de PLA.

Ainda falta, é claro, testar essa relação de modo mais formal e desagregado. Para isso, cabe mencionar de início que, além dessas variáveis independentes de interesse, adotamos algumas variáveis independentes como controle. São elas: GastosMin, que mede a porcentagem do orçamento ministerial controlada pelo partido de cada deputado em cada ano, ponderando pelo tempo de ocupação dos ministérios ${ }^{19}$; AnosMandato, que mede os anos de mandato na Câmara dos Deputados (contando desde 1945) que cada parlamentar já havia servido em cada momento considerado; nPartCarreira, que mede o número de partidos diferentes a que cada parlamentar já havia sido filiado (contando desde 1980) em cada ano; AnosPartAtual, que mede o número de anos que cada deputado já havia tido no partido que estava em cada momento considerado ${ }^{20}$; ufPLA que mede a execução de emendas de bancadas estaduais no estado de cada deputado em cada ano.

Cabe relembrar também que a própria variável dependente observada em um dado ano $t_{0}$, ou seja $D g o v_{t 0}$, aparecerá defasada temporalmente como variável explicativa para corrigir AR, no formato $\operatorname{ggov}_{\mathrm{t}-[1: 3]}$. Praticamente todos os modelos testados só deixam de ter $\operatorname{AR}(>1)$ quando Dgov é defasada em ao menos três anos. Por fim, como mencionado 
previamente, as duas variáveis instrumentais tipo $\mathrm{GMM}^{21}$ testadas nos modelos são: $D g o v_{t \leq-6}$ e ExecOrcUF $F_{\mathrm{t} \leq 0}$. A primeira opção, um instrumento interno, é a própria variável endógena $D g o v$, em defasagem temporal longa, permitindo estimação por GMM na linha do proposto por Arellano-Bond (1991). Em nossos modelos, defasagens menores do que seis anos para esse instrumento voltam a introduzir $\mathrm{AR}(>1)$, como consequência do tipo de problema de instrumentos fracos com defasagens próximas da AR a ser tratada, apontado por Anderson e Hsiao (1981). A segunda opção, que mede a porcentagem de execução orçamentária federal no estado de cada deputado em cada ano, é um instrumento externo aos modelos, levando à estimação GMM no seu formato de variáveis instrumentais generalizado. Ambos os instrumentos foram testados com diferentes opções de defasagem temporal para tentar evitar ao máximo o problema de excesso de instrumentos, típico de estimações GMM com esse tipo de instrumentalização. Em linhas gerais, nenhuma diferença foi encontrada.

Começamos apresentando o resultado de três modelos simples que radicalizam o problema de $\mathrm{AR}$, ao não corrigirem nem sequer $\mathrm{AR}(1)$. $\mathrm{O}$ primeiro inclui apenas a defasagem de um ano da variável Coa, o segundo apenas a defasagem de um ano da variável PLA e o terceiro, as defasagens de um ano de ambas as variáveis. A Tabela 2 mostra os resultados.

Vale observar que, na linha do que Figueiredo e Limongi (2005) também encontraram em seus modelos logísticos, o poder preditivo do modelo apenas com Coa é bastante bom, enquanto apenas com PLA é próximo de zero, sendo que a adição de $P L A$ nada contribui ao poder preditivo do modelo em que há apenas Coa. Mas é possível notar que, nos três modelos, Coa e PLA aparecem estatisticamente significantes aos níveis mais rigorosos de exigência, apresentando também coeficientes com o sinal esperado: pertencer à coalizão de governo ou ter muitas emendas ao orçamento executadas diminui a distância entre o ponto ideal dos deputados e o do governo. Ocorre, no entanto, que nenhum dos três modelos passa no teste de Wooldridge (2003) para $\operatorname{AR}(1)$ ou nos testes de Breusch-Godfrey para $\operatorname{AR}(\geq 2)$, isto é, há autocorrelação nos erros. Nesse sentido, as inferências sobre os coeficientes não são confiáveis e é preciso testar sua robustez à correção de AR.

Para resolver esse problema, passamos a incluir agora a defasagem de $D g o v_{t-[1: k]}$ no lado direito da equação, em que $k$ é o máximo de anos de 
Tabela 2

Modelos Lineares em Painel com Efeitos Fixos

Variável Dependente é $\operatorname{Dgov}_{\mathrm{t} 0}$

\begin{tabular}{|c|c|c|c|c|c|c|}
\hline & M-1 & & M-2 & & M-3 & \\
\hline $\mathrm{Coa}_{t 0}$ &,- 225 & $(, 01)^{* * *}$ & & &,- 218 & $(, 01)^{* * *}$ \\
\hline $\operatorname{Coa}_{t-1}$ &,- 085 & $(, 01)^{* * *}$ & & &,- 077 & $(, 01)^{* * *}$ \\
\hline \multirow[t]{2}{*}{$P L A_{t-1}$} & & &,- 183 & $(, 02)^{* * *}$ &,- 084 & $(, 01)^{* * *}$ \\
\hline & & &,- 153 & $(, 01)^{* * *}$ &,- 057 & $(, 01)^{* * *}$ \\
\hline \multicolumn{7}{|c|}{ p-valor do teste de Wooldridge (2003) ${ }^{\mathrm{a}}$ : } \\
\hline AR(1): & $<0,00$ & $* * *$ & $<0,00$ & $* * *$ & $<0,00$ & $* * *$ \\
\hline \multicolumn{7}{|c|}{ p-valor do teste de Breusch-Godfrey: } \\
\hline $\mathrm{AR}(2)$ & $<0,00$ & $* * *$ & $<0,00$ & $* * *$ & $<0,00$ & $* * *$ \\
\hline $\mathrm{AR}(3)$ : & $<0,00$ & $* * *$ & $<0,00$ & $* * *$ & $<0,00$ & $* * *$ \\
\hline \multicolumn{7}{|c|}{ Medidas de ajuste dos modelos: } \\
\hline Adj.-within & 0,41 & & 0,07 & & 0,42 & \\
\hline RSS & 117,46 & & 186,01 & & 115,09 & \\
\hline $\mathrm{N}$ & 4.601 & & 4.601 & & 4.601 & \\
\hline
\end{tabular}

Fonte: Estimação própria.

${ }^{a}$ A abordagem proposta por Wooldridge (2003) testa a presença de correlação serial através de procedimento que não depende das características assintóticas de painéis longos (grande número de anos).

Obs.: A amostra tem N. deputados=1278, T=1-15. Erro padrão robusto aparece entre parênteses. p-valores: ${ }^{* * *}<0,001 ; * *<0,01 ; *<0,05$.

defasagem considerados para essa variável. A estimação com efeitos fixos desse tipo de modelo, conhecido como dinâmico, requer o uso de GMM. Partimos do último modelo da Tabela 1, isto é, o que possui tanto Coa como PLA, ambos defasados em um ano:

$\operatorname{Dgov}_{i t}=\gamma_{1} \operatorname{Dgov}_{i t-[1: k]}+\beta_{1} \operatorname{Coa}_{i t-[0: 1]}+\beta_{2} P L A_{i t-[0: 1]}+e_{i t}$

Apresentamos essa especificação $\operatorname{com} k=2$ e $\operatorname{com} k=3$, estimando com os dois instrumentos diferentes mencionados anteriormente para efeito de comparação. Os resultados podem ser encontrados na Tabela 3.

Os resultados desse conjunto de modelos mostram, antes de tudo, que apenas as especificações com $k>=3$, isto é ao menos $\operatorname{Dgov}_{\mathrm{t}-[1: 3]}$, conseguem passar ao mesmo tempo nos testes de Sargan e de AR. Quando a defasagem de $D g o v$ é de apenas um e dois anos e o instrumento utilizado é a própria $D g o v$, o problema de AR é até corrigido, mas a validade do instrumento é rejeitada pelo teste de Sargan. Já quando a defasagem

DADOS - Revista de Ciências Sociais, Rio de Janeiro, vol. 57, nº 3, 2014 
Fabricio Vasselai e Umberto G. Mignozzetti

Tabela 3

Modelos Difference-GMM com Efeitos Fixos, sem a Inclusão de Controles e Defasagem Temporal de Coa e PLA em 1 Ano

Variável Dependente é $\operatorname{Dgov}_{t 0}$

\begin{tabular}{|c|c|c|c|c|c|c|c|c|}
\hline & M-4 & & M-5 & & M-6 & & M-7 & \\
\hline \multicolumn{4}{|c|}{$\begin{array}{l}\text { Instrumento } \\
\text { GMM: }\end{array}$} & \multicolumn{2}{|c|}{$D g o v_{t 5-6}$} & \multicolumn{3}{|c|}{ ExecOrcUF $_{t 50}$} \\
\hline$D g o v_{t-1}$ & 130 & $(, 13)$ & 207 & $(, 11)$ &,- 396 & $(, 02)^{* * *}$ &,- 341 & $(, 02)^{* * *}$ \\
\hline$D g o v_{t-2}$ & ,046 & $(, 13)$ & ,055 & $(, 11)$ &,- 097 & $(, 02)^{* * *}$ &,- 131 & $(, 03)^{* * * *}$ \\
\hline$D g o v_{t-3}$ & & &,- 221 & $(, 06)^{* * *}$ & & &,- 066 & $(, 03)^{* * * *}$ \\
\hline $\mathrm{Coa}_{t 0}$ &,- 133 & $(, 01)^{* * *}$ &,- 098 & $(, 02)^{* * *}$ &,- 141 & $(, 01)^{* * *}$ &,- 093 & $(, 02)^{* * * *}$ \\
\hline Coat $_{t-1}$ &, 010 & $(, 02)$ & ,020 & $(, 02)$ &,- 070 & $(, 01)^{* * *}$ &,- 051 & $(, 01)^{* * * *}$ \\
\hline$P L A_{t 0}$ &,- 002 & $(, 03)$ & ,009 & $(, 03)$ &,- 019 & $(, 02)$ &,- 013 & $(, 02)$ \\
\hline$P L A_{t-1}$ &,- 007 & $(, 03)$ &,- 015 & $(, 03)$ &,- 024 & $(, 02)$ &,- 020 & $(, 02)$ \\
\hline \multicolumn{9}{|c|}{ p-valor do teste de validade dos instrumentos: } \\
\hline Sargan &, 004 & & 135 & & ,130 & & 0,218 & \\
\hline \multicolumn{9}{|c|}{ p-valores do teste de autocorrelação serial: } \\
\hline $\mathrm{AR}(2)$ & ,919 & & ,402 & & ,002 & & ,686 & \\
\hline $\operatorname{Cor}(\hat{\gamma})$ & ,264 & & ,206 & &, 532 & & 489 & \\
\hline N usado: & 1.390 & & 1.131 & & 2.063 & & 1.546 & \\
\hline
\end{tabular}

Fonte: Estimação própria.

Obs.: A amostra tem N. deputados=1.278, T=1-15. Erro padrão robusto aparece entre parênteses. p-valores: ${ }^{* *}<0,001,{ }^{* *}<0,01,{ }^{*}<0,05$.

de $D g o v$ é de apenas um e dois anos e o instrumento utilizado é ExecOrcUF, o problema é que AR(2) continua presente. Desse modo, os resultados daqui em diante serão apresentados apenas para especificações com $D \operatorname{gov}_{t-[1: 3]}$ do lado direito das equações - ainda que também tenhamos testado modelos especificados com $D g o v_{t-[1: 2]}$, os quais não resultaram em alteração substantiva dos resultados.

Ainda mais importante é notar que, em qualquer dos quatro modelos dessa tabela, há dois resultados, centrais para nossa questão, que não variam: $P L A$ não tem significância estatística nem em $t$ e nem em $t-1$. Nem mesmo se considerarmos p-valores a corte de 0,10 , o que já seria bastante generoso levando em conta o tamanho da amostra efetiva usada nos modelos. Enquanto $\mathrm{Co}_{t 0}$ tem significância estatística em todos os modelos ao corte de 0,001, além de sinal esperado. A principal variação de resultado entre as estimações feitas com os dois tipos de instrumento refere-se a $\mathrm{Coa}_{\mathrm{t}-1}$, que só é estatisticamente significante quando o instrumento utilizado é ExecOrcUF. Isso significa que, em re- 
lação ao efeito que pertencer à coalizão no ano anterior às votações nominais causa sobre o posicionamento dos deputados nessas mesmas votações, não há um resultado robusto às diferenças de instrumento GMM utilizado. Mas, certamente o pertencimento às coalizões no mesmo ano das votações é, esse sim, resultado robusto a todas as especificações de modelos.

Aliás, como se sabe, em modelos de tipo painel os resultados também podem ser especialmente sensíveis a especificações das defasagens temporais. Isto equivale a dizer que falsos negativos ou falsos positivos podem ser encontrados quando se considera a dimensão temporal usando defasagens incorretas ou insuficientes. Para verificar a robustez dos resultados anteriores frente a outras especificações temporais, apresentamos a seguir uma série de modelos com diferentes defasagens temporais para Coa e para PLA. Incluímos também o conjunto de variáveis de controle descritas anteriormente para controlar se alteram os resultados encontrados até aqui ${ }^{22}$. Trata-se basicamente da seguinte especificação:

$\operatorname{Dgov}_{t i}=\gamma_{1: 3} \operatorname{Dgov}_{i t-[1: 3]}+\beta_{1} \operatorname{Coa}_{i t-[0: q]}+\beta_{2} P L A_{i t-[0: r]}+C+e_{i t}$

em que $q$ é o número máximo de anos defasados para Coa e varia em cada modelo, r é o número máximo de anos defasados para PLA e também varia em cada modelo; e C é o conjunto de variáveis de controle e seus respectivos coeficientes. Os resultados encontram-se nas Tabelas 4 e 4 a, uma para cada instrumento utilizado neste artigo.

Os resultados desses modelos são, em linhas gerais, os mesmos encontrados anteriormente. Ou seja, o pertencimento à coalizão no mesmo ano em que o posicionamento dos parlamentares é considerado $\left(\mathrm{Coa}_{t 0}\right)$ demonstra ser, invariavelmente, estatisticamente significante aos níveis mais rigorosos de corte, bem como apresenta o sinal esperado: isto é, pertencer à coalizão de governo diminui a distância entre o ponto ideal dos deputados e o ponto ideal do governo. Quando a instrumentalização é feita via ExecOrcUF, até mesmo as defasagens de Coa têm significância e sinal esperado, sugerindo um efeito adicional sobre a proximidade entre o ponto ideal dos deputados e o ponto ideal dos presidentes, quando os deputados já participavam da coalizão nos anos anteriores.

Ao mesmo tempo, a porcentagem de emendas executadas apresenta um resultado bem diferente. $P L A_{\mathrm{t}-[0: r]}$ não possui significância para 
Fabricio Vasselai e Umberto G. Mignozzetti

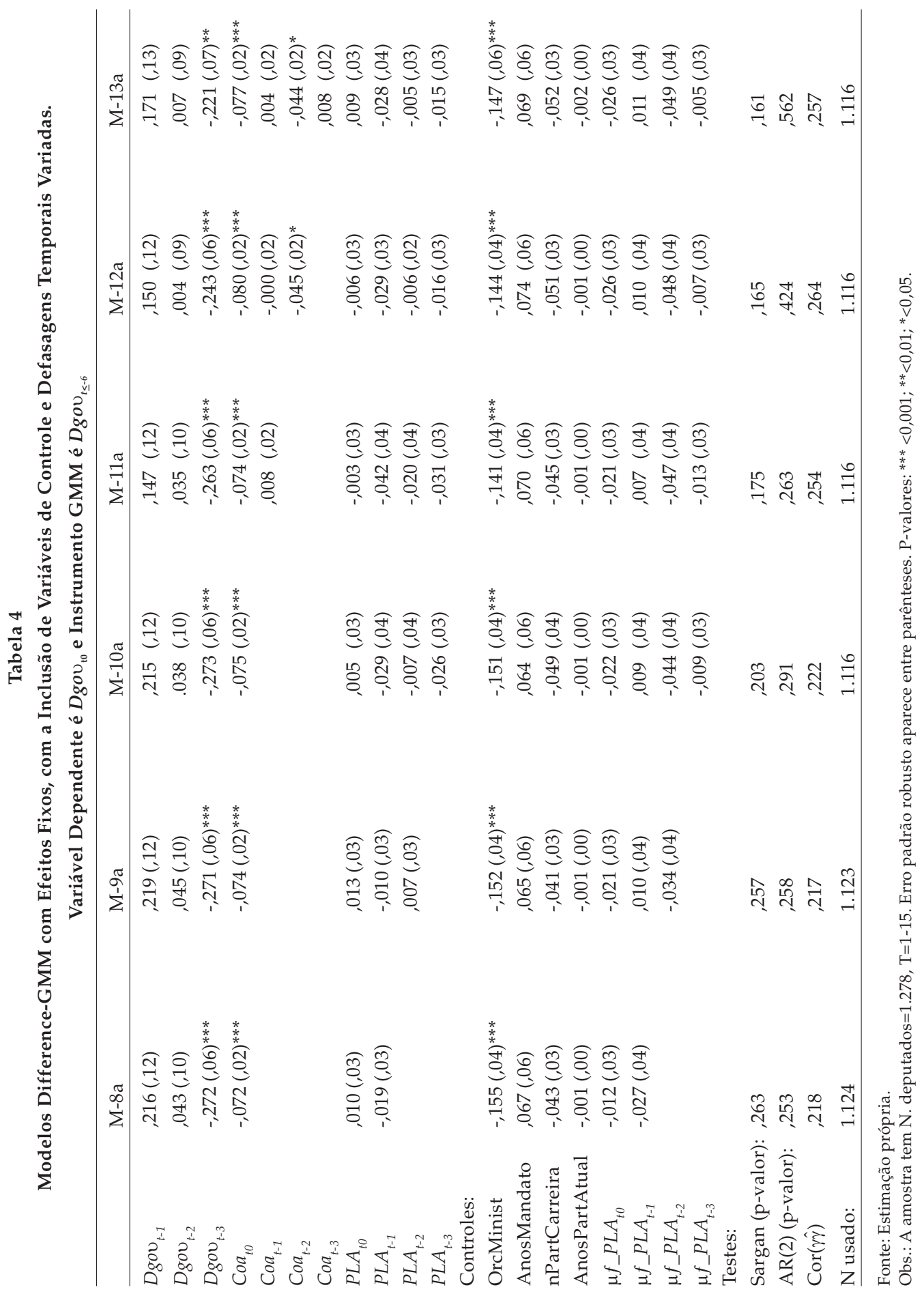


O Efeito das Emendas ao Orçamento no Comportamento Parlamentar...

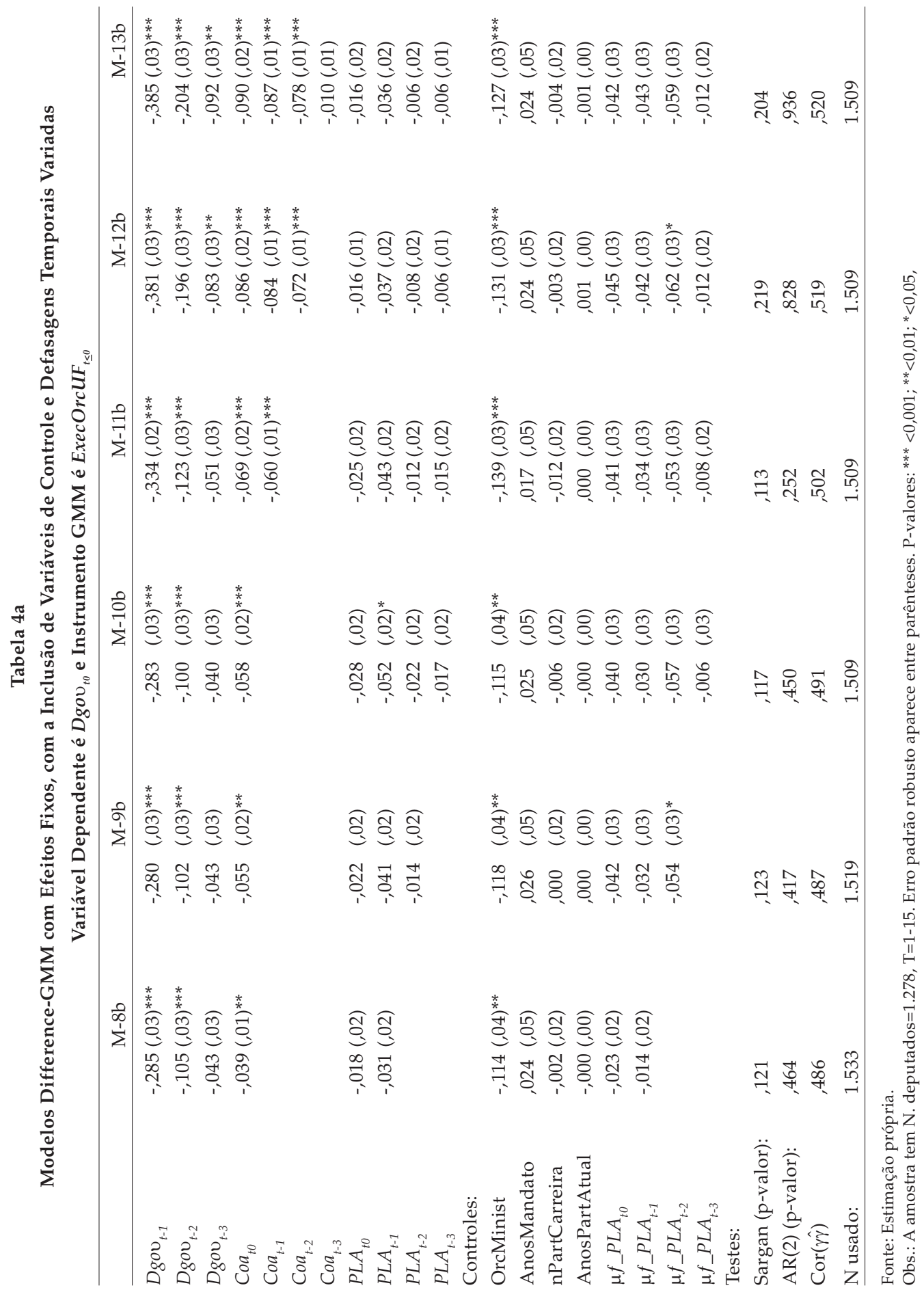

DADOS - Revista de Ciências Sociais, Rio de Janeiro, vol. 57, nํㅡ, 2014 
nenhuma ordem de defasagem $r$, em nenhum modelo, com uma única exceção, na Tabela $4 \mathrm{a}$, em que $P L A_{\mathrm{t}-1}$ aparece significante ao nível de 0,05 em um modelo. Este é um resultado nada robusto em face das diversas especificações e, na verdade, dependente de um modelo muito específico e pouco plausível: instrumentalizado com ExecOrcUF, especificado com $q=0$ e $r=3$. De resto, em nenhum modelo e com nenhum dos instrumentos GMM utilizados, PLA jamais volta a mostrar significância estatística tal como o fazia antes da correção de AR. O mais próximo que se encontra de relevância para as emendas, segundo nossos resultados, é a significância estatística para as emendas estaduais, não individuais, liquidadas pelo governo em alguns dos modelos instrumentalizados por ExecOrcUF. Trata-se, porém, novamente, de um resultado não robusto às diferentes especificações e instrumentalizações.

Enquanto isso, o único controle que mostra ser sempre estatisticamente significante e com o sinal esperado é precisamente aquele que complementa Coa, isto é, OrcMinist (orçamento ministerial controlado pelo partido do deputado em um dado ano). Isso significa dizer que a despeito da especificação de modelos utilizados, quanto mais orçamento ministerial controlado pelo partido de um dado deputado no ano de uma dada votação, mais ele tende a se aproximar do ponto ideal do governo. Estimamos também modelos com defasagens temporais de OrcMinist (não apresentados aqui por questão de espaço) e, no geral, todas as suas defasagens também têm significância estatística ao nível de 0,001 , bem como sinal esperado. O resultado dessa variável de controle mostra que sua inclusão não apenas não altera o resultado geral encontrado para Coa ou para PLA, como fornece ainda um indício adicional do papel relevante desempenhado pelas coalisões de governo no apoio dos parlamentares à agenda dos presidentes.

Esse conjunto de resultados deixa poucas dúvidas de que, uma vez corrigida AR e instrumentalizados os modelos GMM com instrumentos válidos, não encontramos evidência empírica para considerar que emendas ao orçamento realmente impactem no apoio dos deputados à agenda dos presidentes. Testamos também modelos adicionais, interagindo Coa e PLA para tentar captar algum efeito adicional das emendas sobre a pertença ou ausência às coalizões, além de outros modelos interagindo $P L A$ e o tamanho dos partidos na Câmara, para tentar verificar o possível impacto das emendas sobre deputados de partidos satélites, isto é, que não possuem ministérios mas nem por isso pertencem necessariamente à oposição (para a importância de diferenciar o 
que são partidos da situação com ou sem ministérios, ver Freitas, 2008; Limongi e Freitas, 2005). Por questão de parcimônia e espaço, não apresentamos esses resultados aqui, mas em nenhum caso foram diferentes do discutido anteriormente. Ou seja, o pertencimento à coalizão, no sentido de integrar as equipes ministeriais, continua sendo uma variável com significância estatística e sinal esperado, enquanto a execução das emendas mantém-se estatisticamente não significante e, nesses testes adicionais, até mesmo passa a ter por vezes o sinal contrário ao esperado.

\section{CONSIDERAÇÕES FINAIS}

Os resultados encontrados neste trabalho não permitem sustentar a hipótese tão popularmente difundida de que a execução, por parte do Executivo, das emendas ao orçamento feitas pelos deputados tem impacto sistemático relevante sobre como esses parlamentares votam na Câmara dos Deputados. Pelo contrário, uma vez corrigida a autocorrelação serial presente na proximidade entre o ponto ideal de deputados e o ponto ideal do governo, o papel das emendas jamais se mostra estatisticamente significante. Diga-se de passagem que, do ponto de vista do poder preditivo em modelos bivariados, mesmo sem essa correção o poder preditivo da execução das emendas sobre a proximidade entre parlamentares e Executivo é praticamente nulo, enquanto o pertencimento à coalizão governamental tem poder preditivo bastante elevado.

Mais importante, os resultados sobre o papel da pertença à base de governo sobre a proximidade dos pontos ideais de deputados e do governo são expressivos também do ponto de vista de inferência estatística. A presença dos partidos dos deputados nas equipes ministeriais dos presidentes tem efeito estatisticamente robusto a diferentes especificações de modelos, a diferentes defasagens temporais e ao uso de diferentes instrumentos. Além disso, encontramos uma indicação adicional de que mesmo a quantidade do orçamento ministerial controlado pelos partidos dos deputados também parece exercer impacto sobre a proximidade do ponto ideal dos votos desses parlamentares com relação aos pontos ideais dos presidentes em um determinado ano.

Como discorremos de início, isso não nos permite afirmar algo de concreto sobre se os parlamentares utilizam ou não os recursos aprovados em suas emendas para levá-los a redutos eleitorais, tampouco é possível dizer se com isso eles conseguem aumentar suas probabilidades de 
reeleição. $\mathrm{Ou}$, ainda, se as emendas parlamentares tendem a alterar a agenda ideal dos presidentes ou o caráter nacional versus local das políticas de alocação de gastos. Sobre essas questões, muitas vezes misturadas com o papel das emendas sobre o comportamento parlamentar, há uma série de bons trabalhos acadêmicos analisando-as e debatendo-as. Nosso trabalho somente nos permite fazer afirmações sobre esse ponto específico; isto é, que não há razões empíricas suficientes para afirmar, como é costumeiro, que as emendas dos parlamentares ao orçamento seriam uma verdadeira moeda de troca na obtenção de apoio parlamentar.

Não pretendemos com isso encerrar o debate sobre essa questão. Pelo contrário, nossa intenção é renovar o interesse pelo tema. Mais pesquisas sobre o assunto, inclusive que avancem no tratamento do fator tempo e das suas nuances devidamente consideradas, são muito bem-vindas. De resto, pretendemos tão-somente defender a cautela. Do ponto de vista acadêmico, precaução quanto às questões metodológicas que precisam ser desenvolvidas a fim de evitar os falsos positivos e os falsos negativos no que se refere ao uso das emendas para angariar apoio parlamentar, e, portanto, cautela com as usuais conclusões definitivas de que as emendas individuais ao orçamento desempenhariam um papel de verdadeiras moedas de troca nas relações Executivo-Legislativo. Afinal, trata-se de papel sobre o qual não abundam indícios empíricos científicos incontroversos. Pelo contrário, há controvérsias - e como mostramos, falta de evidência empírica - suficientes para, no mínimo, suscitarem mais dúvidas do que, academicamente, viemos recentemente levantando. E mais dúvidas do que a militância política e o fervor midiático sobre o assunto usualmente se permitem ter.

(Recebido para publicação em novembro de 2012)

(Reapresentado em outubro de 2013) (Aprovado para publicação em abril de 2014) 


\section{O Efeito das Emendas ao Orçamento no Comportamento Parlamentar...}

\section{NOTAS}

1. Um dos trechos em que Figueiredo e Limongi melhor explicam a questão está em um de seus textos sobre as emendas ao orçamento: “Tomemos o bordão neo-institucionalista a sério: resultados não podem ser derivados mecanicamente das preferências. Em outras palavras: mesmo que, devido à influência da arena eleitoral, soubéssemos as preferências dos parlamentares quanto ao tipo de política que patrocinariam, estas não podem ser deduzidas daquelas. Dito de maneira positiva: a capacidade de os parlamentares aprovarem políticas depende da organização ou estrutura do processo decisório, mais especificamente, da distribuição dos direitos parlamentares".

2. Vale ressaltar que esse cenário pode ser modificado muito em breve, uma vez que à medida que este artigo é publicado, tramita a Proposta de Emenda à Constituição (PEC) 565/2006, já aprovada na Câmara e remetida ao Senado Federal, propondo tornar impositiva a execução das emendas parlamentares ao orçamento. Curioso é reparar que se trata de proposta saudada por alguns com base em problemas cujos diagnósticos, como mostramos aqui, são imprecisos ou estão ainda em aberto.

3. Esse ponto, por sua vez, pode ser desdobrado em outras necessidades de comprovação empírica correlatas: para que um parlamentar tenha interesse em levar verbas a redutos eleitorais em um sistema eleitoral proporcional de lista aberta, seria necessário supor: 1) que esse parlamentar tem votos concentrados em um ou poucos locais dentro do estado que representa; 2) que esse parlamentar tem de que isso é um padrão, ou seja, de que repetirá nas eleições seguintes esse mesmo tipo de desempenho; 3) que os eleitores nos redutos eleitorais têm como distinguir aquele parlamentar como origem dos recursos levados. Para uma discussão sobre o assunto, abordando defensores e críticos dessas suposições, ver Ames (2001), Cheibub e Camargos (2002) e Ricci (2003).

4. Em um ambiente de informação imperfeita os deputados poderiam supor que emendas ao orçamento ajudassem em suas chances de se reelegerem, mesmo que isso não seja verdade. Assim como o Executivo poderia acreditar que liberando verbas de emendas poderia solidificar ainda mais a sua base de apoio parlamentar, mesmo que empiricamente as emendas pouca ou nenhuma diferença fizessem, haja vista que o montante envolvido tem pouquíssimo peso sobre o orçamento da União (ver mais à frente). Afinal, essas informações são complexas e imperfeitas na hora do cálculo estratégico: nesse sentido, não seria um erro estratégico liberar emendas ou trabalhar para aumentar suas chances de liberação. Poderia ser, sim, considerada uma ação míope por parte dos deputados ou por parte do Executivo, mas não um deslize estratégico grave.

5. Figueiredo e Limongi (2002:313-314) explicam em detalhes: "a Constituição reconhece o direito de o Legislativo emendar os projetos enviados pelo Executivo. No caso do Projeto de Lei Orçamentária (PLO), o artigo 166 da Constituição estabelece que cabe ao Executivo estimar as receitas e que as emendas congressuais são aceitas desde que indiquem 'os recursos necessários, admitidos apenas os provenientes de anulação de despesa, excluídas as que incidem sobre: a) dotações para pessoal e seus encargos; b) serviço da dívida; c) transferências tributárias constitucionais para Estados, Municípios e Distrito Federal'. Como a Lei noำ 4.320 / 64 veda o cancelamento das dotações destinadas às despesas correntes, a intervenção do Congresso na confecção 
do orçamento resume-se praticamente ao remanejamento das despesas com investimentos".

6. De todo modo, é claro que mesmo considerando a questão como um jogo repetido, devemos levar em conta que esse jogo estaria repleto de informações imperfeitas e ameaças/promessas de recompensas ou punições que não teriam, a priori, nenhum crédito em si mesmas. Do lado dos parlamentares, não estaria claro (apesar do forte apelo no senso comum) que liberação de emendas aumentaria a chance de reeleição ou que o Executivo liberaria emendas caso eles apoiassem suas políticas. Do lado do governo, não existiria nenhuma forma de contrato que garantisse um acordo verbal de um parlamentar que tivesse prometido ajudar o governo em troca de apoio. Da mesma forma, se o governo fosse negociar com os líderes, as lideranças dos partidos de oposição teriam de abrir mão de suas agendas partidárias (o que poderia custar-lhes seus cargos) em troca da agenda do governo e, assim, pôr em prática uma agenda que poderia acabar com suas chances de sobrevivência política.

7. Os autores comentam sobre a não inclusão dessas variáveis em notas de fim do texto. Sobre popularidade presidencial, afirmam na nota número 12 que ela "Não influencia diretamente o apoio legislativo em nossos dados. Não incluímos popularidade presidencial na equação do apoio legislativo por causa de alta colinearidade inversa dessa variável com os gastos das emendas. O padrão de correlação de ordem zero provê evidência de que essa é a melhor especificação viável" (tradução nossa). O problema é que, salvo haja multicolinearidade quase perfeita entre popularidade presidencial e execução de emendas, o que seria estranho, a forte relação entre elas é exatamente a razão para que a popularidade presidencial devesse aparecer na equação do apoio legislativo, já que assim poderia testar se o efeito das emendas resiste à sua inclusão. Já sobre porque deixam de fora coalescência e heterogeneidade da coalizão, os autores comentam na nota 15: "Coalescência ministerial e heterogeneidade da coalizão não aparecem na equação preditiva do apoio legislativo. Procedimentos diagnósticos e testes de especificação sugerem fortemente que não há relação direta significativa entre essas variáveis e o suporte eleitoral em nossos dados. Além da preocupação com overspecification e inflação indevida dos erros padrão, incluir heterogeneidade da coalizão aqui pode também reduzir sua efetividade como um instrumento nas regressões de primeiro estágio" (tradução nossa). É claro que incluí-las na equação do apoio legislativo reduziria sua efetividade como instrumento da equação das emendas, mas isso não é razão para não incluí-las, pelo contrário: é de se questionar se variáveis com tamanha possibilidade teórica de impacto sobre o apoio legislativo podem funcionar como instrumentos fortes de execução de emendas ao orçamento. Seria interessante verificar se passam no teste de Sargan e se são instrumentos fortes, isto é, se trazem elevado $\mathrm{R}^{2}$ parcial no primeiro estágio.

8. De fato, replicamos os modelos presentes em Raile, Pereira e Power (2011) com os dados e script para software STATA fornecidos pelos autores, para realizar os testes que não são apresentados em seu artigo. Contudo, ao invés de estimar por método de mínimos quadrados em três estágios (3SLS) como os autores - que é uma opção para a qual não há implementação, naquele software, dos testes de ajuste dos modelos ou de validade da instrumentação - estimamos por máxima verossimilhança (MLE) através do comando sem do STATA. MLE é equivalente ou superior ao 3SLS para modelos de equações estruturais e possui, já implementada, uma série de testes de pós-estimação. O resultado dessa replicação é que nenhum dos modelos dos autores 
se aproxima de passar nos testes necessários. A título de ilustração, seu modelo principal (de número 1 no artigo mencionado) tem: como medida de ajuste, $p>C h i^{2}=0,000$ (quando o necessário é não ser estatisticamente significante); como medidas de erro, RMSEA=0,176 (quando o necessário é ser próxima de 0) e $\operatorname{Pr}[\operatorname{RMSEA}<=0,05]=0,000$ (quando o ideal é ser maior que 0,90); como medidas de baseline comparison, CFI e TLI iguais a 0,83 e 0,76 respectivamente (quando o necessário é que sejam não menores do que 0,95$)$.

9. Repetimos também os modelos através de estimação por system GMM, de Blundell-Bond (1998), que visa tratar a possibilidade de instrumentos serem fracos. Apesar de nesse caso ter se mostrado mais difícil passar no teste de validade dos instrumentos, na maioria dos casos os resultados das inferências e dos coeficientes não apresentaram alteração alguma.

10. O site possui informações também para 1995, ano inicial do primeiro mandato de Fernando Henrique Cardoso, mas cobrem apenas alguns poucos deputados. Provavelmente, inclui apenas as execuções de emendas posteriores à mudança das normas sobre emendamento orçamentário que foram consolidadas naquele ano.

11. Esses dados podem ser encontrados em: http://www2.camara.leg.br/atividade-legislativa/orcamentobrasil/orcamentouniao/loa/ Acessado em 10/09/2010.

12. Cabe ressalvar que, a cada ano, foram incluídos apenas os deputados que apresentaram alguma emenda individual ao orçamento.

13. Nas poucas votações em que não havia informação sobre indicação de voto por parte do líder do governo, utilizamos como sua proxy a votação em plenário por parte do líder do partido do presidente. A coincidência entre esse e a indicação do líder do governo é de praticamente $100 \%$.

14. O algoritmo retira da amostra casos em que não houve pelo menos $10 \%$ de discordância, procedimento usualmente adotado por outros autores na análise de votações nominais. Outra decisão importante é que são excluídos os deputados que não participam de pelo menos 10\% das votações. Essas decisões, pode-se argumentar, poderiam gerar algum viés de seleção. Entretanto, são justificáveis do ponto de vista metodológico pois, no primeiro caso, se não há discordância, não há como analisar o peso da votação na diferenciação de comportamento dos deputados. No segundo caso, um deputado que votou em pouquíssimas votações acaba por não ter participação tão expressiva a ponto de influenciar na decisão de modo mais geral sobre as políticas. E isso torna mais robusto o cálculo feito via W-Nominate.

15. Alguém poderia argumentar também sobre o porquê de não se usar a média anual da disciplina de cada deputado com relação ao líder do governo ao invés do escore do W-Nominate. Argumentamos, primeiro, que um deputado que vota em $60 \%$ das votações e sempre com o líder do governo em um dado ano terá 100\% de concordância com este líder, maior do que a de um deputado que votasse $90 \%$ das votações com $90 \%$ de concordância. Isso induziria a um viés pelo fato de que seriam atribuídos escores iguais a deputados que tiveram participações diferentes. O W-Nominate ajuda a solucionar essa discrepância.

16. Como se trata de uma variável dependente com piso e teto pré-determinados, poder-se-ia questionar por que não utilizar sua versão transformada por log - o que ajudaria a normalizar a distribuição dos resíduos e impediria predição fora do piso e do teto. De fato, rodamos todos os modelos também com essa variável transformada 
por $\ln (\operatorname{Dgov+1})$. Os resultados foram quase idênticos, tanto no que se refere aos parâmetros quanto às medidas de ajuste e aos testes. Na verdade, o teste de Sargan pontua até melhor. Dada tal similaridade e o fato que os modelos aqui são explicativos e não preditivos, optamos por apresentar os resultados com a variável não transformada pela facilidade de leitura dos dados.

17. Nos dados disponíveis nos relatórios de execução orçamentária das emendas ao orçamento, da Comissão Mista de Orçamento do Congresso, os valores liquidados das emendas em cada ano são os que melhor representam a execução dos valores aprovados e empenhados.

18. Seguimos o banco de classificações ministeriais de Vasselai (2009), atualizando para os anos posteriores a 2007.

19. Um exemplo dessa ponderação por tempo de ocupação dos ministérios: se em um dado ano um dado partido ocupou três ministérios de um total de 20 por quatro meses e então quatro ministérios de um total de 20 por nove meses, a porcentagem ponderada de ocupação nos ministérios desse partido para esse ano seria: $3 / 20 * 4 / 12+$ $5 / 20 * 9 / 12=0,15 * 0,3 \overline{3}+0,25 * 0,75=0,05+0,1875=0,2375$.

20. Para as variáveis Experiência e AnosPartAtual, a contabilização considerou anos completos ou períodos de mais de seis meses para os anos não completos. Sobre a variável AnosPartAtual, cerca de $5 \%$ das mudanças partidárias não possuíam informação de data: nesses casos consideramos o primeiro ano eleito ou nomeado para algum cargo pelo partido, segundo consta das informações biográficas dos ex-deputados na Câmara dos Deputados ou mesmo de outras fontes públicas.

21. Falamos aqui especialmente dos instrumentos GMM, pois nesse tipo de estimação por padrão todas as outras variáveis não utilizadas como instrumentos GMM são utilizadas como instrumentos normais adicionais - seguindo as especificações que possuem nos modelos.

22. Além disso, estimamos também todas as combinações possíveis de defasagem temporal das variáveis Coa e PLA, com e sem a presença de controles, e para diferentes defasagens de Dgov. Embora não tragamos essa ampla série de resultados por questão de economia de espaço, vale notar que não apresentam resultados diversos dos apresentados no corpo deste artigo. 


\section{O Efeito das Emendas ao Orçamento no Comportamento Parlamentar...}

\section{REFERÊNCIAS BIBLIOGRÁFICAS}

ALSTON, Lee J. e MUELLER, Bernardo. (2001), Coalition Stability and the Gains from Trade between the Executive and the Legislature in Brazil. Trabalho apresentado na 5a Conferência Annual da International Society for New Institutional Economics. São Francisco, 13-15 de setembro.

AMES, Barry. (2001), The Deadlock of Democracy in Brazil. Ann Arbor, University of Michigan Press.

AMORIM NETO, Octavio. (1994), "Formação de Gabinetes Presidenciais no Brasil: Coalizão versus Cooptação". Nova Economia, vol. 4, no 1, pp. 9-34.

(1998), Of Presidents, Parties, and Ministers: Cabinet Formation and Legislative Decision-making under Separation of Powers. Tese de doutorado em Ciência Política, University of California, San Diego.

(2000), “Gabinetes Presidenciais, Ciclos Eleitorais e Disciplina Legislativa no Brasil". DADOS - Revista de Ciências Sociais, vol. 43, no 3, pp. 479-519.

e SANTOS, Fabiano. (2003), “O Segredo Ineficiente Revisto: O que Propõem e o que Aprovam os Deputados Brasileiros". DADOS-Revista de Ciências Sociais, vol. 46, no 4, pp. 661-698.

ANDERSON, Theodore W. e HSIAO, Cheng. (1981), "Estimation of Dynamic Models with Error Components". Journal of the American Statistical Association, vol. 76, no 375, pp. 598-606.

ARELLANO, Manuel e BOND, Stephen. (1991), “Some Tests of Specification for Panel Data: Monte Carlo Evidence and an Application to Employment Equations". The Review of Economic Studies, vol. 58, no 2, pp. 277-297.

BLUNDELL, Richard e BOND, Stephen. (1998), "Initial Conditions and Moment Restrictions in Dynamic Panel Data Models". Journal of Econometrics, vol. 87, pp.115-143.

BRASIL. (1988), Constituição da República Federativa do Brasil. Brasília, Centro de Documentação e Informação da Câmara dos Deputados.

CHEIBUB, José A. e CAMARGOS, Malco. (2002), Electoral Strategies and Electoral Success in an Open-PR System. Yale, Yale University. Mimeo.

DESPOSATO, Scott W. (2006), “The Impact of Electoral Rules on Legislative Parties: Lessons from the Brazilian Senate and Chamber of Deputies". The Journal of Politics, vol. 68, no 4, pp. 1015-1027.

FIGUEIREDO, Argelina e LIMONGI, Fernando. (1998), “Bases Institucionais do Presidencialismo de Coalizão". Lua Nova, no 44, pp. 81-106.

(1999), Executivo e Legislativo na Nova Ordem Constitucional. Rio de Janeiro, FGV Editora.

(2002), "Incentivos Eleitorais, Partidos e Política Orçamentária". DADOS - Revista de Ciências Sociais, vol. 45, no 2, pp. 303-344.

(2005), "Processo Orçamentário e Comportamento Legislativo: Emendas Individuais, Apoio ao Executivo e Programas de Governo". DADOS - Revista de Ciências Sociais, vol. 48, no 4, pp. 737-776. 
(2008), Política Orçamentária no Presidencialismo de Coalizão. Rio de Janeiro, FGV Editora.

FREITAS, Andréa M de. (2008), Migrações Partidárias na Câmara dos Deputados. Dissertação de Mestrado, Departamento de Ciência Política, Universidade de São Paulo, São Paulo.

LAMOUNIER, Bolívar. (1994), “A Democracia Brasileira de 1985 à Década de 1990: ASíndrome da Paralisia Hiperativa”, in J. P. R. Velloso (ed.), Governabilidade, Sistema Politico e Violência Urbana. Rio de Janeiro, José Olympio.

LEONI, Eduardo L. (2002), "Ideologia, Democracia e Comportamento Parlamentar: A Câmara dos Deputados (1991-1998)". DADOS - Revista de Ciências Sociais, vol. 45, no 3, pp. 361-386.

LIMONGI, Fernando e FREITAS, Andréa M de. (2005), Migração Partidária e Comportamento Legislativo. Trabalho apresentado no 29o Encontro Anual da Anpocs. Caxambu, MG, 25-29 de outubro.

MAINWARING, Scott. (1991), "Politicians, Parties and Electoral Systems: Brazil in Comparative Perspective". Comparative Politics, vol. 24, no 1, pp. 21-43.

MENEGUELLO, Rachel. (1998), Partidos e Governos no Brasil Contemporâneo: 1985-1997. São Paulo, Paz e Terra.

MESQUITA, Lara. (2009), Emendas ao Orçamento e Conexão Eleitoral na Câmara dos Deputados Brasileira. Dissertação de Mestrado, Departamento de Ciência Política, Universidade de São Paulo, São Paulo.

NICOLAU, Jairo. (2000), “Disciplina Partidária e Base Parlamentar na Câmara dos Deputados no Primeiro Governo Fernando Henrique Cardoso: 1995-1998”. DADOS Revista de Ciências Sociais, vol. 43, no 4, pp. 709-735.

PEREIRA, Carlos e MUELLER, Bernardo. (2002), “Comportamento Estratégico em Presidencialismo de Coalizão: As Relações entre Executivo e Legislativo na Elaboração do Orçamento Brasileiro". DADOS-Revista de Ciências Sociais, vol. 45, no2 2, pp. 265-301.

. (2003), "Partidos Fracos na Arena Eleitoral e Partidos Fortes na Arena Legislativa: A Conexão Eleitoral no Brasil". DADOS - Revista de Ciências Sociais, vol. 46, no 4, pp. 735-771.

PEREIRA, Carlos e ORELLANA, Salomon. (2009), "Hybrid Political Institutions and Governability: The Budgetary Process in Brazil". Journal of Politics in Latin America, vol. 1, no 3, pp. 57-79.

PEREIRA, Carlos e RENNÓ, Lucio. (2001), “O que é que o Reeleito Tem? Dinâmicas Político-institucionais Locais e Nacionais nas Eleições de 1998 para a Câmara dos Deputados". DADOS - Revista de Ciências Sociais, vol. 44, no 2, pp. 133-172.

. (2007), “O que é que o Reeleito Tem? O Retorno: O Esboço de uma Teoria da Reeleição no Brasil". Revista de Economia Política, vol. 108, no 4, pp. 664-683.

PRAÇA, Sérgio. (2013), "Conversão Institucional: O Caso da Comissão Mista de Orçamento", in Corrupção e Reforma Orçamentária no Brasil, 1987-2008. São Paulo, Annablume, pp. 159-206. 
O Efeito das Emendas ao Orçamento no Comportamento Parlamentar...

PRAIS, S. J. e WINSTEN, C. B. (1954), “Trend Estimators and Serial Correlation”. Cowles Commission Discussion Paper: Statistics no 383, Chicago.

RAILE, Eric; PEREIRA, Carlos e POWER, Timothy J. (2011), “The Executive Toolbox: Building Legislative Support in a Multiparty Presidential Regime". Political Research Quarterly, vol. 64, no 2, pp. 323-334.

RICCI, Paolo. (2003), “O Conteúdo da Produção Legislativa Brasileira: Leis Nacionais ou Políticas Paroquiais?”. DADOS-Revista de Ciências Sociais, vol. 46, no-4, pp. 699-734.

SANTOS, Fabiano. (2003), O Poder Legislativo no Presidencialismo de Coalizão. Belo Horizonte, Editora UFMG.

VASSELAI, Fabricio. (2009), “Nomeações Ministeriais e Importância Partidária na Democracia de 1946-64: Análises Comparativas em relação à Democracia Atual". Revista Perspectivas, vol. 35, pp. 173-210.

WOOLDRIDGE, Jeffrey M. (2003), Econometric Analysis of Cross Section and Panel Data. Cambridge, MA, The MIT Press.

ZUCCO Jr., Cesar. (2009), “Ideology or What? Legislative Behavior in Multiparty Presidential Settings". The Journal of Politics, vol. 71, no 3, pp. 1076-1092. 


\section{RESUMO}

O Efeito das Emendas ao Orçamento no Comportamento Parlamentar e a Dimensão Temporal: Velhas Teses, Novos Testes

Este artigo analisa se, entre 1996 e 2010, a execução por parte do Executivo das emendas individuais de deputados federais ao orçamento aproximou esses parlamentares das preferências do governo nas votações nominais. Os argumentos que enxergam componente não partidário, personalista e paroquial no apoio parlamentar ao Executivo inspiram-se na influência dessas emendas. No entanto, tanto sua defesa como sua refutação deixam lacunas importantes que mantêm aberta a questão, pois ou desconsideraram o fator tempo nos testes realizados ou seu tratamento metodológico necessita correções. Buscamos superar esses problemas verificando se a distância entre pontos ideais dos parlamentares e da indicação do líder do governo, em dado ano, é influenciada pelas emendas orçamentárias executadas tanto naquele ano como nos anteriores. Propomos modelar tal defasagem temporal entre emendas e apoio parlamentar, corrigindo autocorrelação serial, controlando por medidas de pertencimento à coalizão e lidando com os inerentes problemas de instrumentalização desses modelos.

Palavras-chave: emendas ao orçamento; governabilidade; relações Executivo-Legislativo

\section{ABSTRACT}

The Effect of Budget Amendments in Parliamentary Behavior and the Temporal Dimension: Old Hypotheses, New Tests

In this article the authors examine whether, between 1996 and 2010, the Executive's execution of individual amendments proposed by federal deputies to the budget was responsible for increasing the proximity between parliamentary votes and government preferences in roll-calls. The possible influence of such amendments is where scholars still search for a non-partisan, personal and parochial component of the Legislative support of the Executive. However, both the usual defense of this idea as well as its refutation have considerable gaps to be filled, leaving the question unresolved as time as a factor was not considered in tests or because their methodological approaches require adjustments. This investigation addresses these problems by verifying whether the distance between the ideal points of congressmen and of the appointments by the government chief whip in a given year are influenced by the execution of the budget amendments made by deputies - on the same year as well as on previous ones. We propose to model the temporal between amendments and legislative support, correcting serial auto-correlation, controlling for the coalition membership and dealing with the inherent problems of instrumentalization that come with these types of models.

Keywords: budget amendments; governability; Executive-Legislative relations 
O Efeito das Emendas ao Orçamento no Comportamento Parlamentar...

\section{RÉSUMÉ}

L'Effet des Amendements du Budget sur les Comportements au Parlement et la Dimension Temporelle: Vieilles Thèses, Nouveaux Tests

Dans cet article, on examine si, entre 1996 et 2010, l'exécution par le pouvoir exécutif des amendements individuels proposés par des députés fédéraux au budget, a pu rapprocher ces députés des vues du gouvernement au cours des votes nominaux. C'est dans l'ampleur de ces amendements que résident les arguments qui considèrent de caractère non partisan, personnaliste et de clocher, l'appui que des parlementaires offrent au Pouvoir Exécutif. Mais défendre ou attaquer ces amendements laisse la question sans réponse, puisque dans leur méthodologie, soit ils n'ont pas tenu compte du facteur temps, soit leur approche requiert des rectifications. Dans cette recherche, on a traité ces questions en cherchant à rapprocher les dates des votes des parlementaires et de la désignation du dirigeant du gouvernement avec les amendements budgétaires effectués dans la même année ou dans les années précédentes. On propose ici de modeler cet écart temporel entre amendements et appui parlementaire par la correction d'une auto-corrélation séquentielle, par un contrôle au moyen de mesures d'appartenance à la coalition et enfin en affrontant les problèmes inhérents à l'instrumentalisation de ces modèles.

Mots-clés: amendements au budget; gouvernabilité; rapports pouvoir exécutif-pouvoir législatif

\section{RESUMEN}

El Efecto de las Enmiendas al Presupuesto en el Comportamiento Parlamentario y su Dimensión Temporal: Viejas Tesis, Nuevos Tests

El presente artículo analiza si, entre 1996 y 2010, la ejecución por parte del Ejecutivo de las enmiendas individuales de los diputados al presupuesto federal, acercó los votos de dichos parlamentarios de las preferencias de gobierno en las votaciones nominales. Los argumentos que aún vislumbran un componente no partidista, personalista y parroquial en el apoyo parlamentario al Ejecutivo se inspiran en la influencia de estas enmiendas. Sin embargo, tanto su defensa como su refutación han sido insuficientes, puesto que desconsideran el factor tiempo en los tests realizados o posen un tratamiento metodológico que necesita correcciones. En este texto buscamos superar estos problemas examinando si la distancia entre puntos ideales de los votos de los parlamentarios y de la indicación del líder del gobierno en determinado año es influenciada o no por las enmiendas presupuestarias ejecutadas por el Ejecutivo en el mismo año y anteriores. Proponemos, de este modo, modelar dichos desfasaje temporal entre enmiendas y apoyo parlamentario, corrigiendo la auto-correlación serial, controlando por medidas de pertenencia a la coalición y lidiando con los inherentes problemas de instrumentalización de estos modelos.

Palabras clave: enmiendas al presupuesto; gobernabilidad; relaciones Ejecutivo-Legislativo 